\title{
M4FT-15OR03100421: Status Report on Alkaline Conditioning Studies
}

\author{
S. Das, C. Tsouris, C. Zhang, S. Brown, C.J. Janke, R.T. Mayes, S. Dai \\ Oak Ridge National Laboratory, P.O. Box 2008, Oak Ridge, TN 37831-6053, USA \\ L.-J. Kuo, G. Gill \\ Marine Sciences Laboratory, Pacific Northwest National Laboratory, Sequim, \\ Washington 98382, USA
}

\section{EXECUTIVE SUMMARY}

Significant progress in understanding the role of alkaline conditioning of polyethylene-fiber adsorbent, developed at the Oak Ridge National Laboratory (ORNL), is demonstrated in this report, which is essentially a manuscript prepared for publication in the journal Industrial \& Engineering Chemistry Research of the American Chemical Society. The manuscript describes the influence of various parameters involved in adsorbent alkaline conditioning, including base concentration and duration and temperature of conditioning, on the uranium uptake history by the adsorbent. Various solutions have been used to determine the influence of conditioning parameters including (i) a screening solution containing uranyl nitrate at approximately $8 \mathrm{ppm}$ and sodium bicarbonate and sodium chloride at concentrations similar to those found in seawater, (ii) seawater spiked with approximately $75 \mathrm{ppb}$ uranium, and (iii) natural seawater. In addition to concentration measurements by inductively coupled plasma (ICP) spectroscopy to determine the uranium uptake capacity and kinetics, spectroscopic methods such as Fourier transformed infrared (FTIR) spectroscopy and nuclear magnetic resonance (NMR) spectroscopy were employed to investigate the effect of base treatment on the various chemical bonds of the adsorbent. Scanning electron microscopy (SEM) has also been employed to determine structural effects of the alkali on the adsorbent. The results are summarized as follows:

1. Alkali conditioning is necessary to prepare the adsorbent for uranium uptake. ICP analysis showed that without alkali conditioning, no appreciable uranium adsorption occurs.

2. FTIR showed that the base deprotonates the adsorbent, but also converts amidoxime to carboxylate groups.

3. FTIR showed that formation of carboxylate groups is irreversible and reduces the selectivity of the adsorbent toward uranium.

4. NMR showed that alkali conditioning leads also to the formation of cyclic imidedioxime, which is suspected to bind uranium, vanadium, iron, copper, and other metals.

7. Uptake of $\mathrm{V}, \mathrm{Fe}$, and $\mathrm{Cu}$ follows the same trend as that of uranium. Uptake of $\mathrm{Ca}, \mathrm{Mg}$, and $\mathrm{Zn}$ ions increases with increasing $\mathrm{KOH}$ conditioning time due to formation of carboxylate groups.

5. SEM showed that long conditioning times may also lead to adsorbent degradation.

6. The optimal conditioning parameters are: $0.44 \mathrm{M} \mathrm{KOH}, 70{ }^{\circ} \mathrm{C}$, for 1 hour.

The results of this study are useful in the selection of optimal values of the parameters involved in preparing amidoxime-based adsorbent for uranium uptake from seawater. Additional work is still ongoing to provide a complete understanding of the chemistry of base conditioning and its role on the functioning of the adsorbent. 


\title{
Enhancing Uranium Uptake by Amidoxime Adsorbent in Seawater: An investigation for optimum alkaline conditioning parameters
}

\author{
S. Das ${ }^{\dagger}$, C. Tsouris,${ }^{*}$ C. Zhang, ${ }^{\dagger}$ S. Brown, ${ }^{\text {T }}$ C.J. Janke,${ }^{\dagger}$ R.T. Mayes,${ }^{\dagger}$ L.-J. Kuo,${ }^{\ddagger}$ G. Gill,${ }^{\ddagger}$ S. Dai ${ }^{\dagger T}$ \\ ${ }^{\dagger}$ Oak Ridge National Laboratory, P.O. Box 2008, Oak Ridge, TN 37831-6053, USA \\ ${ }^{\mathrm{T}}$ Department of Chemistry, University of Tennessee, TN, USA \\ "Marine Sciences Laboratory, Pacific Northwest National Laboratory, Sequim, \\ Washington 98382, USA \\ Submitted for publication in
}

Industrial and Engineering Chemistry Research

May 2015

Notice: This manuscript has been authored by UT-Battelle, LLC under Contract No. DE-AC0500OR22725 with the U.S. Department of Energy. The United States Government retains and the publisher, by accepting the article for publication, acknowledges that the United States Government retains a non-exclusive, paid-up, irrevocable, world-wide license to publish or reproduce the published form of this manuscript, or allow others to do so, for United States Government purposes. The Department of Energy will provide public access to these results of federally sponsored research in accordance with the DOE Public Access Plan (http://energy.gov/downloads/doe-public-access-plan). 


\title{
Enhancing Uranium Uptake by Amidoxime Adsorbent in Seawater: An investigation for optimal alkaline conditioning parameters
}

\author{
S. Das ${ }^{\dagger}$, C. Tsouris,${ }^{* \dagger}$ C. Zhang, ${ }^{\dagger}$ S. Brown, ${ }^{\text {T }}$ C.J. Janke,${ }^{\dagger}$ R.T. Mayes,${ }^{\dagger}$ L.-J. Kuo,${ }^{\ddagger}$ G. Gilll, ${ }^{\dagger}$ S. Dai ${ }^{\dagger T}$ \\ ${ }^{\dagger}$ Oak Ridge National Laboratory, P.O. Box 2008, Oak Ridge, TN 37831-6053, USA \\ ${ }^{\mathrm{T}}$ Department of Chemistry, University of Tennessee, TN, USA \\ ${ }^{\ddagger}$ Marine Sciences Laboratory, Pacific Northwest National Laboratory, Sequim, \\ Washington 98382, USA
}

\begin{abstract}
A high-surface-area polyethylene-fiber adsorbent (AF160-2) has been developed at the Oak Ridge National Laboratory (ORNL) by radiation-induced graft polymerization of acrylonitrile and itaconic acid. The grafted nitriles were converted to amidoxime groups by treating with hydroxylamine. The amidoximated adsorbents were then conditioned with potassium hydroxide $(\mathrm{KOH})$ by varying different reaction parameters such as $\mathrm{KOH}$ concentration $(0.2,0.44$, and 0.6 $\mathrm{M})$, duration $(1,2$, and $3 \mathrm{~h})$, and temperature $\left(60,70\right.$, and $\left.80^{\circ} \mathrm{C}\right)$. Adsorbent screening was then performed with simulated seawater solutions containing sodium chloride and sodium bicarbonate, at concentrations found in seawater, and uranium nitrate at a uranium concentration of $\sim 7-8 \mathrm{ppm}$ and $\mathrm{pH} 8$. FTIR and solid state NMR indicated that a fraction of amidoxime groups was hydrolyzed to carboxylate during $\mathrm{KOH}$ conditioning. The uranium adsorption capacity in the simulated seawater screening solution gradually increased with conditioning time and temperature for all $\mathrm{KOH}$ concentrations. It was also observed that the adsorption capacity increased with an increase in concentration of $\mathrm{KOH}$ for all the conditioning times and temperatures. AF160-2 adsorbent samples were also tested with natural seawater using flowthrough experiments to determine uranium adsorption capacity with varying $\mathrm{KOH}$ conditioning time and temperature. Based on uranium loading capacity values of several AF160-2 samples, it was observed that changing $\mathrm{KOH}$ conditioning time from 3 to $1 \mathrm{~h}$ at 60,70 , and $80^{\circ} \mathrm{C}$ resulted in increase of the uranium loading capacity in seawater, which did not follow the trend found in laboratory screening with stimulated solutions. Longer $\mathrm{KOH}$ conditioning times lead to significantly higher uptake of divalent metal ions, such as calcium and magnesium, which is a result of amidoxime conversion into less selective carboxylate. Scanning electron microscopy showed that long conditioning times may also lead to adsorbent degradation.
\end{abstract}

Keywords: Uranium adsorbent, seawater, amidoxime, adsorbent conditioning 


\section{Introduction}

Capturing uranium from seawater is a challenging task that requires consideration of chemical, transport, and process design aspects. The concentration of uranium in seawater is on the order of $1.4 \times 10^{-8} \mathrm{~mol} \mathrm{~L}^{-1}(3.3 \mathrm{ppb})$ and is the anionic triscarbonato-uranate $(\mathrm{VI})\left[\mathrm{UO}_{2}\left(\mathrm{CO}_{3}\right)_{3}\right]^{4-}$ species under the prevailing conditions. ${ }^{1}$ The major problems pertaining to the development of a suitable uranium recovery system from seawater are due to the low concentration, the stability of triscarbonato uranate (VI), and the large excess of competing ions. ${ }^{1-3}$ Triscarbonato uranate (VI) has a high stability constant that limits the choice of functional groups for uranium recovery from seawater. Poly(acrylamidoxime) (pAO) has been found to be chemically suitable for uranium recovery from seawater. ${ }^{1-20}$ However, the major challenge for making uranium recovery economically viable is to develop an adsorbent that has a high uranium sorption rate and a high uptake capacity.

For this current study, the pAO adsorbents have been prepared by electron beam induced grafting of acrylonitrile (AN) and itaconic acid (ITA) onto a "hollow-gear" shaped poly(ethylene-) host fiber and subsequent conversion of AN to AO groups by reacting the precursor sorbent with hydroxylamine. One of the key factors effecting uranium uptake from seawater in pAO-based adsorbents is alkaline conditioning. It is a well-reported fact that conditioning of pAO sorbent with alkaline solution significantly enhances the uranium loading capacity. It is claimed that the enhancement is due to two primary reasons: i) increased hydrophilicity ${ }^{4-18}$ and ii) conversion of open chain amidoxime into cyclic imidedioxime. ${ }^{18-20}$ Omichi et. al. observed that uranium adsorption was virtually zero without alkaline conditioning of the pAO adsorbent, while the adsorbent showed appreciable quantity of uranium uptake on conditioning with $2.5 \mathrm{wt}$ $\% \mathrm{KOH}$ (in 3:1 methanol-water mixture) at $80{ }^{\circ} \mathrm{C}$ for 10 minutes. ${ }^{5}$ They also demonstrated that the uranium adsorption capacity on $\mathrm{KOH}$ conditioning at room temperature for one week was still lower than the adsorption capacity after $\mathrm{KOH}$ conditioning at $80^{\circ} \mathrm{C}$ for 10 minutes. Egawa et. al. reported significant increment of uranium adsorption from seawater, while treating pAO resin with $1 \mathrm{M} \mathrm{NaOH}$ at $30{ }^{\circ} \mathrm{C}$ for $72 \mathrm{~h}$, as compared to without base treatment. ${ }^{6-8}$ According to these authors, alkaline treatment leads to swelling of the micropores, which in turn increases permeation of the targeted $\mathrm{UO}_{2}{ }^{2+}$ to the fixed binding sites, leading to enhanced uranium adsorption capacity. In another work, Kabay described the effect of $1 \mathrm{M} \mathrm{NaOH}$ conditioning time. It was found that 48 hours of alkaline treatment was optimum for the highest uranium 
adsorption capacity. ${ }^{9}$ Kago et. al. demonstrated $0.1 \mathrm{M} \mathrm{NaOH}$ conditioning at $80{ }^{\circ} \mathrm{C}$ for $40-50$ minutes was optimum for a better uranium adsorption rate than that at $30{ }^{\circ} \mathrm{C}$ for 40 hours. ${ }^{10}$ There are several other reports of alkaline conditioning of pAO sorbent with $2.5 \mathrm{wt} \% \mathrm{KOH}$ : at $60{ }^{\circ} \mathrm{C}$ for $1 \mathrm{~h}^{11-17}$ as well as at $80{ }^{\circ} \mathrm{C}$ for 30 minutes. ${ }^{18}$ Kang et. al. reported that the amidoxime slowly converts to carboxylate during base conditioning with $\mathrm{KOH}$ at $80{ }^{\circ} \mathrm{C} .{ }^{21}$

Although several reports have been published on this topic, no systematic work has been performed so far to investigate the optimum reaction parameters of alkali conditioning for the pAO-based adsorbents. In the present work, such parameter as concentration, temperature, and time of the $\mathrm{KOH}$ treatment of amidoxime adsorbent have been studied with the objective to identify the optimum conditioning parameters for highest uranium loading capacity from seawater and lowest structural effects on the adsorbent. The focus was on the uranium uptake capacity of the adsorbent from simulated screening solution of high uranyl concentration after a 24-h exposure and also on the uptake of uranium and other metal ions from natural seawater after a 56-day exposure.

\section{Materials and Methods}

\section{Materials}

All chemicals were reagent-grade or higher. Acrylonitrile (AN); Itaconic acid (ITA); tetrahydrofuran (THF); methanol; dimethylsulfoxide (DMSO); N,N- dimethylformamide (DMF); hydroxylamine hydrochloride ( $\mathrm{HA}-\mathrm{HCl})$; and potassium hydroxide $(\mathrm{KOH})$ were obtained from Sigma-Aldrich. Ultrapure water (18 $\mathrm{M} \Omega \mathrm{cm}^{-1}$, Thermo scientific Nanopore) was used in the preparation of $\mathrm{HA}-\mathrm{HCl}$ and $\mathrm{KOH}$ solutions. Hollow-gear, high-surface-area polyethylene fibers (PE) were prepared by melt-spinning at Hills, Inc. (Melbourne, FL), using polylactic acid (PLA) as the co-extrusion polymer. Uranyl nitrate hexahydrate $\left(\mathrm{UO}_{2}\left(\mathrm{NO}_{3}\right)_{2} \cdot 6 \mathrm{H}_{2} \mathrm{O}, \mathrm{B} \& \mathrm{~A}\right.$ Quality), sodium bicarbonate $\left(\mathrm{NaHCO}_{3}, \mathrm{ACS}\right.$ Reagent, Aldrich) and sodium chloride ( $>99 \%$, Aldrich) were used to prepare the simulated seawater, and a $1000 \mathrm{ppm}$ uranium (U) standard solution (High Purity Standards, North Charleston, USA) was used to prepare the ICP standards.

\section{Preparation of adsorbent}

The adsorbent fibers were prepared by radiation-induced graft polymerization (RIGP) at the NEO Beam Electron Beam Cross-linking Facility (Middlefield, OH). Prior to irradiation, the 
PLA was removed by submerging the fibers in excess THF at $60{ }^{\circ} \mathrm{C}$ overnight. This process was repeated three times, followed by drying at $50{ }^{\circ} \mathrm{C}$ under vacuum. The pre-weighed dry fiber samples were placed inside double-layered plastic bags within a plastic glove bag and sealed under nitrogen. The fibers were irradiated in the presence of dry ice using a translation table cycling the fibers for 16 passes under the electron beam to a dose of approximately $200 \pm 10 \mathrm{kGy}$ using 4.4-4.8 MeV electrons and $1 \mathrm{~mA}$ current from an RDI Dynamitron electron beam machine. The total irradiation time was approximately 22 minutes. After irradiation, the fibers were immersed in 300-mL pressure bottle containing previously de-gassed grafting solutions consisting of AN and ITA in DMSO. The pressure bottles were then placed in an oven at $64{ }^{\circ} \mathrm{C}$ for 18 hours for grafting. After grafting, the fibers were drained from the solution and washed with DMF to remove unreacted monomers and homo polymers, followed by methanol and dried at $50{ }^{\circ} \mathrm{C}$ under vacuum. The grafted fibers (AF160-2) were weighed to determine the percentage degree of grafting (\%DOG), determined gravimetrically from pre-irradiation and post-grafting weights, of co-polymers onto the trunk polymer (Eq 1):

$$
\% D O G=\frac{\left(w t_{A G}-w t_{B G}\right)}{w t_{B G}} x 100
$$

where $w t_{B G}=$ dry weight before grafting and $w t_{A G}=$ dry weight after grafting.

The nitriles in the grafted fiber samples were converted to amidoxime (AO) groups by treating with $10 \mathrm{wt} \%$ hydroxylamine hydrochloride in 50/50 (w/w) water/methanol (previously neutralized with $\mathrm{KOH}$ ) at $80^{\circ} \mathrm{C}$ for $72 \mathrm{~h}$. The samples were then washed under vacuum filtration with deionized water followed by a methanol rinse and allowed to dry at $50{ }^{\circ} \mathrm{C}$ under vacuum.

\section{KOH conditioning of amidoximated AF160-2 fibers}

To determine the optimum $\mathrm{KOH}$ conditioning parameters, the amidoximated AF160-2 fibers were treated with $\mathrm{KOH}$ solution by varying different reaction parameters such as concentration of $\mathrm{KOH}$ solution (i.e., $0.2 \mathrm{M}, 0.44 \mathrm{M}$ and $0.6 \mathrm{M}$ ), duration (i.e., $1 \mathrm{~h}, 2 \mathrm{~h}$, and $3 \mathrm{~h}$ ) and temperature (i.e., $60^{\circ} \mathrm{C}, 70^{\circ} \mathrm{C}$, and $80^{\circ} \mathrm{C}$ ). The $\mathrm{KOH}$-treated samples were immediately filtered and washed with DI water until the $\mathrm{pH}$ was neutral, followed by uranium adsorption determination. 


\section{Simulated seawater screening for uranium adsorption determination}

Batch experiments with synthetic seawater were conducted at the Oak Ridge National Laboratory (ORNL). The simulated seawater screening solution consisting of 193 ppm sodium bicarbonate, 25,600 ppm sodium chloride, and $8 \mathrm{ppm}$ uranium from uranyl nitrate hexahydrate was prepared in $18.2 \mathrm{M} \Omega \mathrm{cm}^{-1}$ water. The $\mathrm{pH}$ of the test solution was approximately 8 . The concentrations of sodium and bicarbonate were selected to be similar to those of seawater. A sample of the solution was collected prior to adsorbent addition to determine the initial uranium concentration. Each of the $\mathrm{KOH}$-conditioned adsorbent samples was then equilibrated with 750 $\mathrm{mL}$ of simulated seawater solution for 24 hours at room temperature with constant shaking at $400 \mathrm{rpm}$. After contacting for 24 hours, an aliquot was taken and the initial and final solutions were analyzed using inductively coupled plasma-optical emission spectroscopy (Perkin Elmer Optima 2100DV ICP-OES) at $367 \mathrm{~nm}$. From the difference in uranium concentration of the solution, the uranium adsorption capacity is determined, using Eq 2. The ICP-OES was calibrated using 6 standard solutions ranging from 0-10 ppm, which were prepared from 1000 ppm uranium in $5 \mathrm{wt} \%$ nitric acid stock solution, and a linear calibration curve was obtained. A blank solution of $2-3 \mathrm{wt} \%$ nitric acid was also prepared, and washouts were monitored between samples to ensure no uranium was carried over into the next analysis. In addition, a solution of 5 ppm yttrium in 2 wt \% nitric acid was used as an internal standard, which was prepared from 1000 ppm stock solution (High-Purity Standards, North Charleston, USA).

$$
\text { Uranium (U) adsorption capacity }=\left[\frac{\text { Initial }[U]\left(\frac{m g}{L}\right)-\text { Final }[U]\left(\frac{m g}{L}\right)}{g \text { of dry adsorbent }}\right] \times \text { Soln. vol. (L) }
$$

In addition to the simulated seawater screening solution, spiked seawater and natural seawater were also used to test the adsorption performance after base conditioning. Spiked seawater of $\sim 75 \mathrm{ppb}$ U concentration was obtained by adding uranyl nitrate hexahydrate in coastal seawater from Charleston, South Carolina. Experiments with natural seawater were performed at the Marine Sciences Laboratory (MSL) of the Pacific Northwest National Laboratory (PNNL) in Sequim, Washington. 


\section{Uranium adsorption kinetics in batch reactors}

One-liter plastic bottles containing coastal seawater spiked with $\sim 75 \mathrm{ppb} U$ were used for batch adsorption experiments. AF160-2 adsorbent $\left(5.2 \mathrm{mg}\right.$ ) conditioned with $0.44 \mathrm{M} \mathrm{KOH}$ at $80{ }^{\circ} \mathrm{C}$ for different time-periods $(45,75,120$ and 180 minutes), were added into the 1 liter plastic bottles, with adsorbent fibers freely suspended in the seawater. An initial seawater sample of $1 \mathrm{~mL}$ was collected prior to addition of adsorbent. The containers were shaken constantly at $100 \mathrm{rpm}$ at room temperature. 1-mL samples were collected periodically using a pipette, over a period of 20 days. Inductively coupled plasma mass spectroscopy (ICP-MS, Thermo Scientific X-Series II) was used for quantitative analysis. Sample aspiration was performed at $100 \mu \mathrm{L} / \mathrm{min}$ with a Teflon SP nebulizer coupled to an Elemental Scientific Inc. $\mathrm{PC}^{3}$ and Fast combination spray chamber. Matrix effects were corrected by adding internal standards containing Bi, In, Sc, Tb, Y (High Purity Standards ICP-MS-IS-2, Perkin-Elmer, consisting of $100 \mathrm{ppb} \mathrm{Bi}$, In, Sc, Tb, Y in 2\% nitric acid) offline before sample introduction. The average of six replicate measurements per sample was used to quantify uranium-238 against a 6-point calibration curve. Prior to sample analysis, semi-quantitative full-mass-range survey scans were collected. Wash out for the instrument was monitored between samples. Standards NASS-5 (seawater) and CASS-6 (seawater), supplied by the National Research Council of Canada, were used for seawater quality-control experiments. High-purity nitric acid (2\%, Optima, Fisher Scientific) was used as the sample diluent and carrier phase.

\section{Field Adsorption Tests}

The adsorbent performance, carried out at PNNL-MSL for 56 days using natural seawater with flow-through columns (Figure 1), was assessed and characterized in terms of adsorbent capacity and kinetics by varying $\mathrm{KOH}$-conditioning parameters, such as temperature and time. The quality of seawater was quantitatively monitored for $\mathrm{pH}$, temperature, salinity, and trace-metal concentrations over the experimental period. The average uranium concentration observed in this study was slightly lower than the normal uranium concentration in seawater of $3.3 \mathrm{ppb}$ [for a salinity of 35 practical salinity units (psu)]. Marine testing was performed using filtered $(0.45$ $\mu \mathrm{m}$ ) seawater at a temperature of $20 \pm 2{ }^{\circ} \mathrm{C}$ and at a flow rate of $250 \mathrm{~mL} / \mathrm{min}$, using an active pumping system (Figure 1). Glass wool and glass beads were used as packing materials for the columns. 


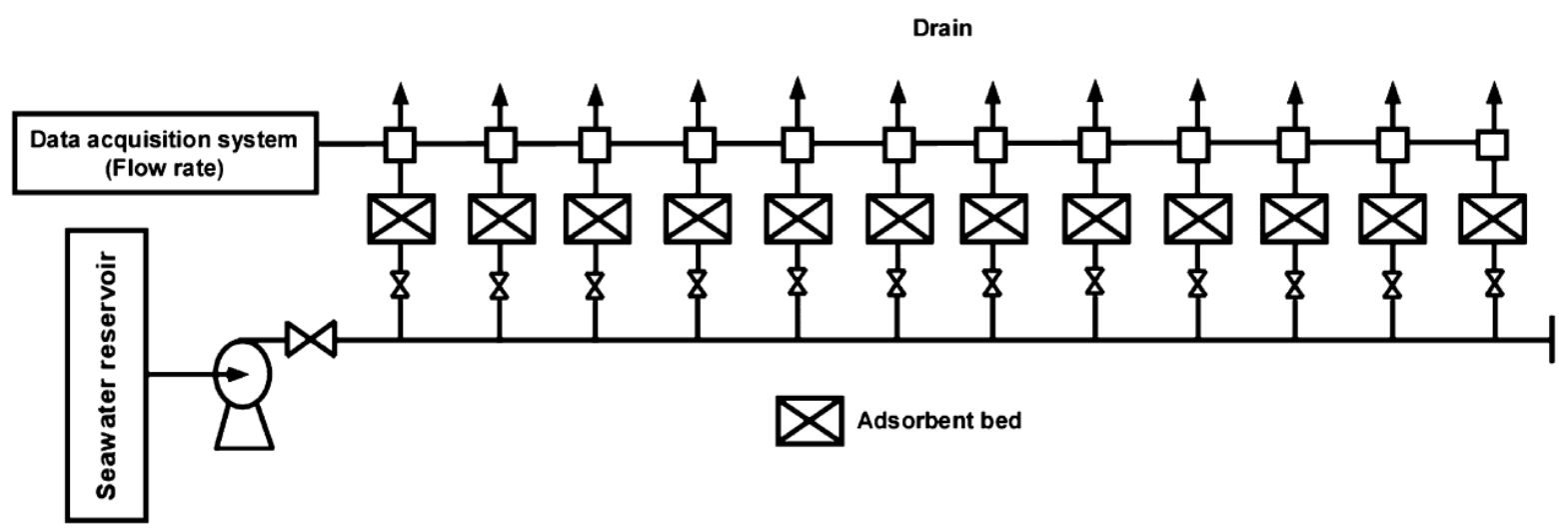

Figure 1. Schematic diagram of flow-through experiments using a parallel configuration at PNNL-MSL.

\section{Sample Handling and Analytical Procedures at PNNL}

The performance of adsorbents in real seawater was assessed at PNNL-MSL. AF160-2 adsorbent samples $(\sim 50 \mathrm{mg})$ were conditioned with $0.44 \mathrm{M} \mathrm{KOH}$ at various temperatures $\left(60,70,80^{\circ} \mathrm{C}\right)$ for different periods (1, 2, 3 hours). The conditioned adsorbents were packed into column (1" diameter, 6" long) fabricated from all plastic components, mostly PVC and polypropylene. Precleaned glass wool and 5-mm glass beads were used to hold the adsorbent fibers in place in the column. The columns were installed in a 24-column all-PVC manifold for seawater flow-through adsorption testing. Figure 1 shows a schematic diagram of the physical layout of natural seawater adsorption testing system in MSL. Ambient seawater was pumped from Sequim Bay, WA, and filtered through $0.45-\mu \mathrm{m}$ polypropylene cartridges for the continuous-flow adsorption experiments. The seawater temperature was controlled at $20 \pm 1^{\circ} \mathrm{C}$ using an all-titanium immersion-heater. The flow rate in each column was controlled at $250-300 \mathrm{~mL} / \mathrm{min}$. Temperature and flow rate were continuously monitored (10 min interval) using a temperature logger equipped with a flexible hermetic sealed RTD sensor probe (OMEGA Engineering, Stamford, CT, USA) and an in-line turbine-style flow sensor (Model DFS-2W, Digiflow Systems), respectively. During the course of the adsorption experiments, seawater salinity and pH were monitored daily using a hand-held salinometer (Model 30, YSI) and pH meter (Orion 3 STAR, Thermo). The seawater exposure time of the adsorption experiments was 56 days.

After the seawater exposure was completed, the adsorbents were removed from the columns and desalted by thoroughly rinsing with DI water. The adsorbents were further dried using a heating 
block and weighed. Digestion of the adsorbents was conducted with a $50 \%$ aqua regia solution at $85^{\circ} \mathrm{C}$ for 3 hours. Samples were further diluted with DI water to be in the desired concentration range before analysis. Analysis of uranium and other trace elements was conducted using a Perkin-Elmer Optima 4300DV inductively coupled plasma optical emission spectrometer (ICPOES), with quantification based on standard calibration curves.

\section{Results and Discussion}

\section{Elemental analysis}

The degree of grafting of AF $160-2$ adsorbent calculated by eq. 1 is $\sim 300 \%$. The weight gain after amidoximation with $10 \mathrm{wt} \%$ hydroxylamine at $80{ }^{\circ} \mathrm{C}$ for $72 \mathrm{~h}$ was $\sim 30 \%$. The results of elemental analysis are shown in Table 1. The nitrogen and oxygen percentage in the electron beam grafted material confirms that AN and ITA are grafted onto PE at an 85:15 weight ratio. The percent weight increase of nitrogen and oxygen in the amidoximated AF160-2 indicates significant conversion of acrylonitrile into amidoxime. The difference in the total percentage of elements confirms deprotonation of the amidoxime functional groups on conditioning with $\mathrm{KOH}$. It can also be postulated that loss of nitrogen with gain of oxygen indicates degradation or conversion to another functional group upon conditioning with $0.44 \mathrm{M} \mathrm{KOH}$.

Table 1. Results of C, H, N, O elemental analysis.

\begin{tabular}{|l|lllll|}
\hline \multirow{2}{*}{ Sample ID } & \multicolumn{5}{|c|}{ Elements (wt \%) } \\
\cline { 2 - 6 } & $\mathrm{C}$ & $\mathrm{H}$ & $\mathrm{N}$ & $\mathrm{O}$ & Total \\
\hline PE hollow fiber & 84.88 & 15.77 & $<0.5$ & $<0.5$ & $\sim 100$ \\
grafted AF160-2 & 67.08 & 8.16 & 18.54 & 6.12 & $\sim 100$ \\
Amidoximated & 48.95 & 8.13 & 20.15 & 22.53 & $\sim 100$ \\
AF160-2 & & & & & \\
AF160-2 - 0.44 M & 45.43 & 7.6 & 16.88 & 24.27 & $\sim 94^{*}$ \\
KOH @80C for 3 h & $(48.33)$ & $(8.08)$ & $(17.95)$ & $(25.82)$ & $(100)$ \\
\hline
\end{tabular}

*The rest $(6 \%)$ is potassium. 


\section{Scanning Electron Microscopy (SEM)}

The SEM images were collected using a JOEL, JSM-6060 SEM at $4 \mathrm{kV}$. The cross sectional pictures of the grafted, amidoximated and dried AF160-2 fibers (Figure 2) clearly demonstrate the hollow gear definition with good gear lengths and increase in fiber diameter after amidoximation. SEM images of KOH-conditioned AF160-2 fibers are shown in Figure 3. As one can see: i) the amidoximated fibers swell further on $\mathrm{KOH}$ conditioning, ii) the fibers retain their hollow gear definition even after 3 hours of $\mathrm{KOH}$ conditioning, and iii) the $\mathrm{AO}$ functional groups onto the fibers seems to be substantially diminished after 24 hours of $\mathrm{KOH}$ conditioning. It should be emphasized here that SEM imaging was performed under vacuum, which also affects the state of the adsorbent fibers.
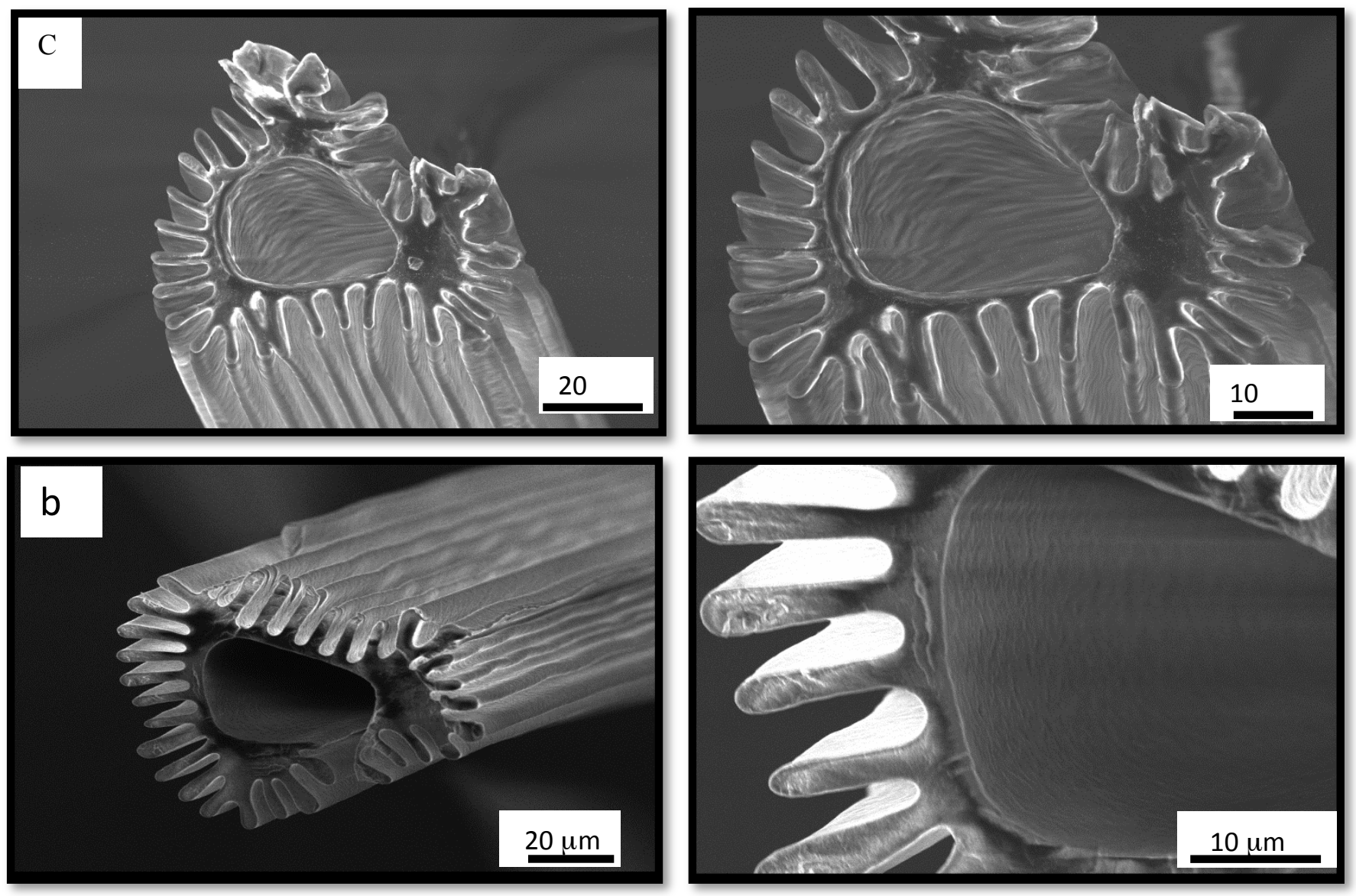

Figure 2. SEM pictures of grafted AF160-2 fiber (a) and amidoximated AF160-2 fiber (b). 

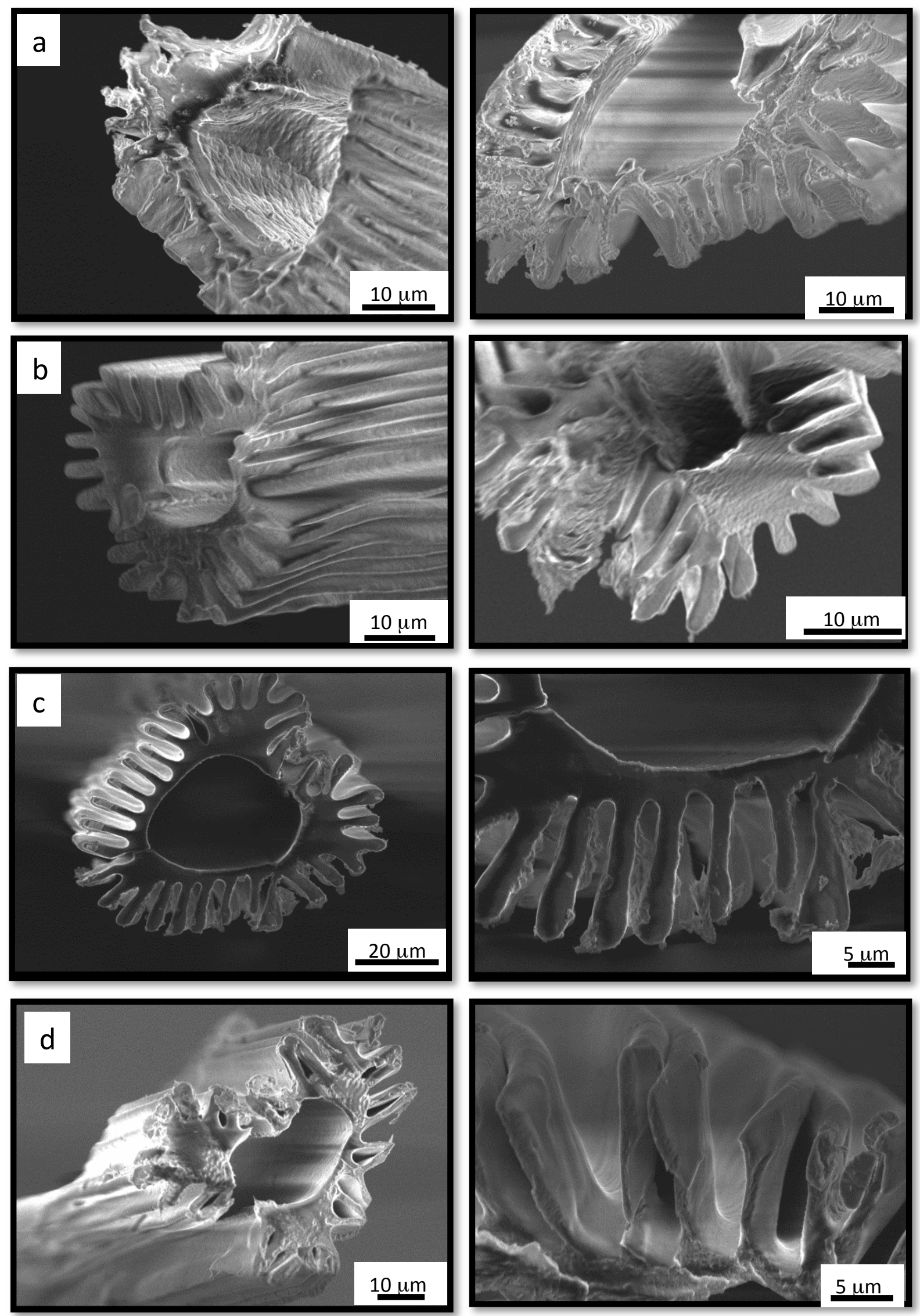

Figure 3. SEM pictures of dried AF160-2 fiber after conditioning with $0.44 \mathrm{M} \mathrm{KOH}$ at $80{ }^{\circ} \mathrm{C}$ for different time-periods: (a) one hour, (b) two hours, (c) three hours and (d) 24 hours. 


\section{Fourier Transform Infrared (FTIR) spectrometry}

FTIR spectra of the AF160-2 fiber samples were collected on a Perkin Elmer Frontier FTIR with a single-bounce diamond attenuated total reflectance (ATR) accessory at $4 \mathrm{~cm}^{-1}$ resolution and averaged over 16 scans. The spectra are shown in Figures 4 and 5. The major peaks in Figure 4 are given in Table 2. The appearance of a stretch at $2247 \mathrm{~cm}^{-1}$ (Figure $4 \mathrm{~b}$ ), representing the $\mathrm{C} \equiv \mathrm{N}$ stretch, suggests grafting of acrylonitrile onto the polyethylene. The split features at $1723 \mathrm{~cm}^{-1}$ and $1670 \mathrm{~cm}^{-1}$ represent the two carbonyl stretches of itaconic acid. The disappearance of nitrile stretch and appearance of $\mathrm{N}-\mathrm{H}\left(3391,3267 \mathrm{~cm}^{-1}\right), \mathrm{C}=\mathrm{N}\left(1644 \mathrm{~cm}^{-1}\right), \mathrm{C}-\mathrm{N}\left(1277 \mathrm{~cm}^{-1}\right)$ and $\mathrm{N}-\mathrm{O}$ $\left(935 \mathrm{~cm}^{-1}\right)$ (Figure $4 \mathrm{c}$ ) can clearly be after conversion of the nitrile to amidoxime (AO).

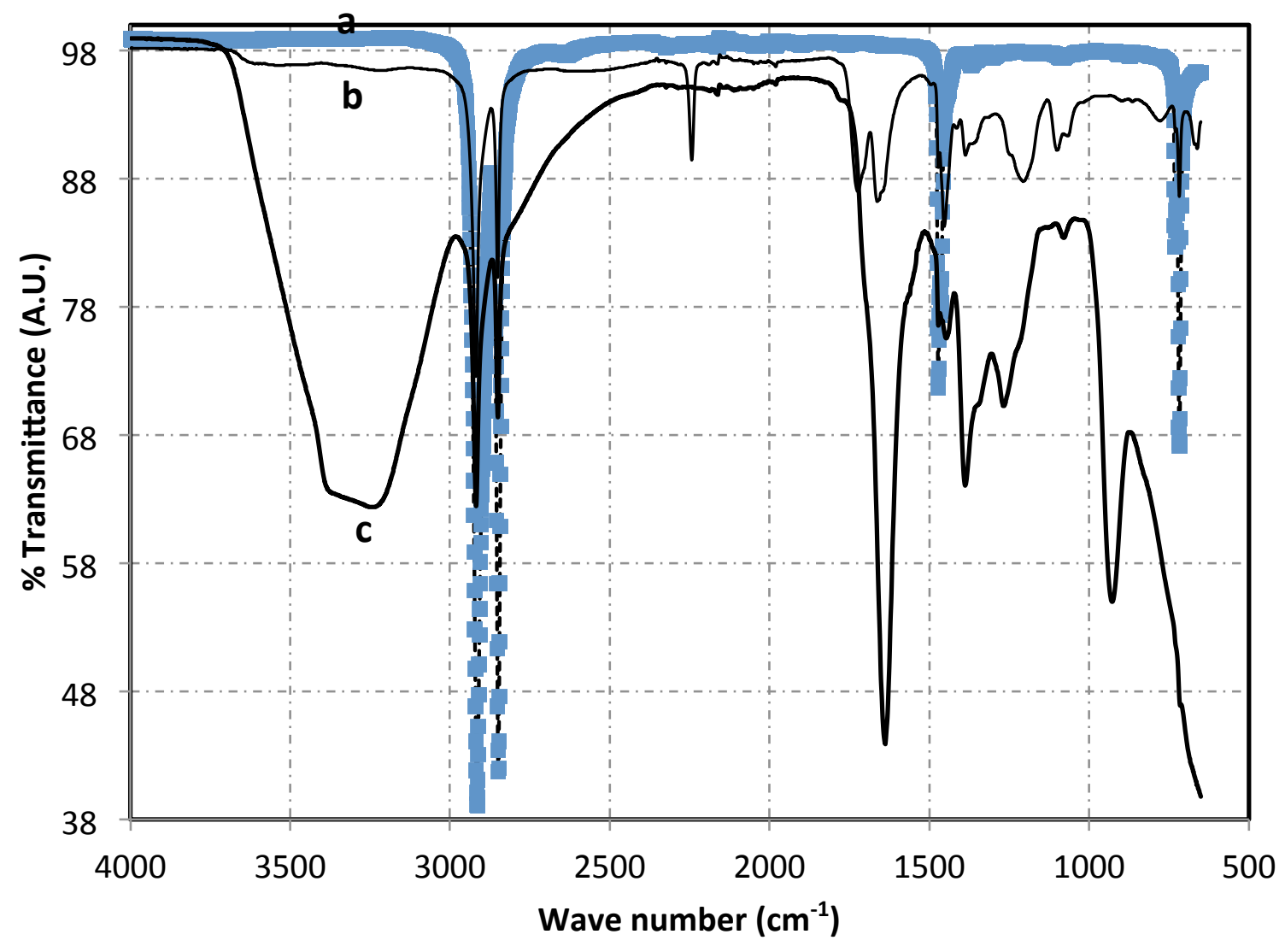

Figure 4. FTIR spectroscopy of (a) PE hollow fiber, (b) grafted PE (AF160-2) fiber and (c) amidoximated AF160-2 fiber. 
Table 2. Assessment of functional groups in AF160-2 adsorbent form characteristic absorption bands in the FTIR shown in Figure 4.

\begin{tabular}{|c|lll|}
\hline Plot & $\begin{array}{l}\text { Characteristic } \\
\text { absorption }\left(\mathrm{cm}^{-1}\right) \text { bands }\end{array}$ & $\begin{array}{l}\text { Functional group } \\
\text { (origin) }\end{array}$ & $\begin{array}{l}\text { Type of } \\
\text { vibration }\end{array}$ \\
\hline \multirow{3}{*}{ a } & 2915,2850 & C-H (PE) & stretching \\
& 1470 & C-H (PE) & bending \\
& 720 & $\mathrm{CH}_{2}(\mathrm{PE})$ & rocking \\
\hline \multirow{5}{*}{$\mathrm{b}$} & $2660-2370$ & $\mathrm{O}-\mathrm{H}$ (ITA) & stretching \\
& 1721,1668 & $\mathrm{C}=\mathrm{O}$ (ITA) & stretching \\
& 1390,1450 & $\mathrm{C}-\mathrm{O}-\mathrm{H}$ (ITA) & bending \\
& 1100,1215 & O-C (ITA) & stretching \\
& 2247 & $\mathrm{C} \equiv \mathrm{N}(\mathrm{AN})$ & stretching \\
\hline $\mathrm{c}$ & $3200-3400$ & $\mathrm{~N}-\mathrm{H}(\mathrm{AO})$ & stretching \\
& 1644 & $\mathrm{C}=\mathrm{N}(\mathrm{AO})$ & stretching \\
& 1277 & $\mathrm{C}-\mathrm{N}(\mathrm{AO})$ & stretching \\
& 935 & N-O (AO) & stretching \\
\hline
\end{tabular}

The effect of $\mathrm{KOH}$ conditioning on the FTIR-ATR of the grafted polymers is shown in Figure 5. The gradual decrease in intensity or disappearance of $\mathrm{N}-\mathrm{O}$ stretch at $935 \mathrm{~cm}^{-1}$ and the C-N stretch at $1277 \mathrm{~cm}^{-1}$ and appearance of the new band at $1565 \mathrm{~cm}^{-1}$, ascribed to either carboxylate formation or the amide II N-H bend, with increasing $\mathrm{KOH}$ conditioning time-period can be described with help of percent transmittance ratios shown on Table 3. The $\mathrm{N}-\mathrm{O}$ vs $\mathrm{C}=\mathrm{N}$ and $\mathrm{C}-\mathrm{N}$ vs $\mathrm{C}=\mathrm{N}$ ratio do not change significantly up to 3 hours $\mathrm{KOH}$ conditioning, but the complete disappearance of $\mathrm{N}-\mathrm{O}$ after 24 hour indicates destruction of the AO functional group.

Appearance of the new band at $1560 \mathrm{~cm}^{-1}$ (i.e., $\mathrm{C}=\mathrm{O}$ stretch) is a result of formation of amide and carboxylate due to hydrolysis of the amidoxime (AO) upon $\mathrm{KOH}$ conditioning (see reaction scheme in Figure 6). The gradual increase in $1560 \mathrm{~cm}^{-1} \mathrm{vs} 1640 \mathrm{~cm}^{-1}$ transmittance ratio also supports the fact that formation of amide/carboxylate increases with $\mathrm{KOH}$ conditioning time. Significant gradual loss in \% transmittance of the N-O stretches at $935 \mathrm{~cm}^{-1}$ with increasing $\mathrm{KOH}$ conditioning time suggests gradual degradation of active AO binding sites and thus may completely disappear after 24 hours. 


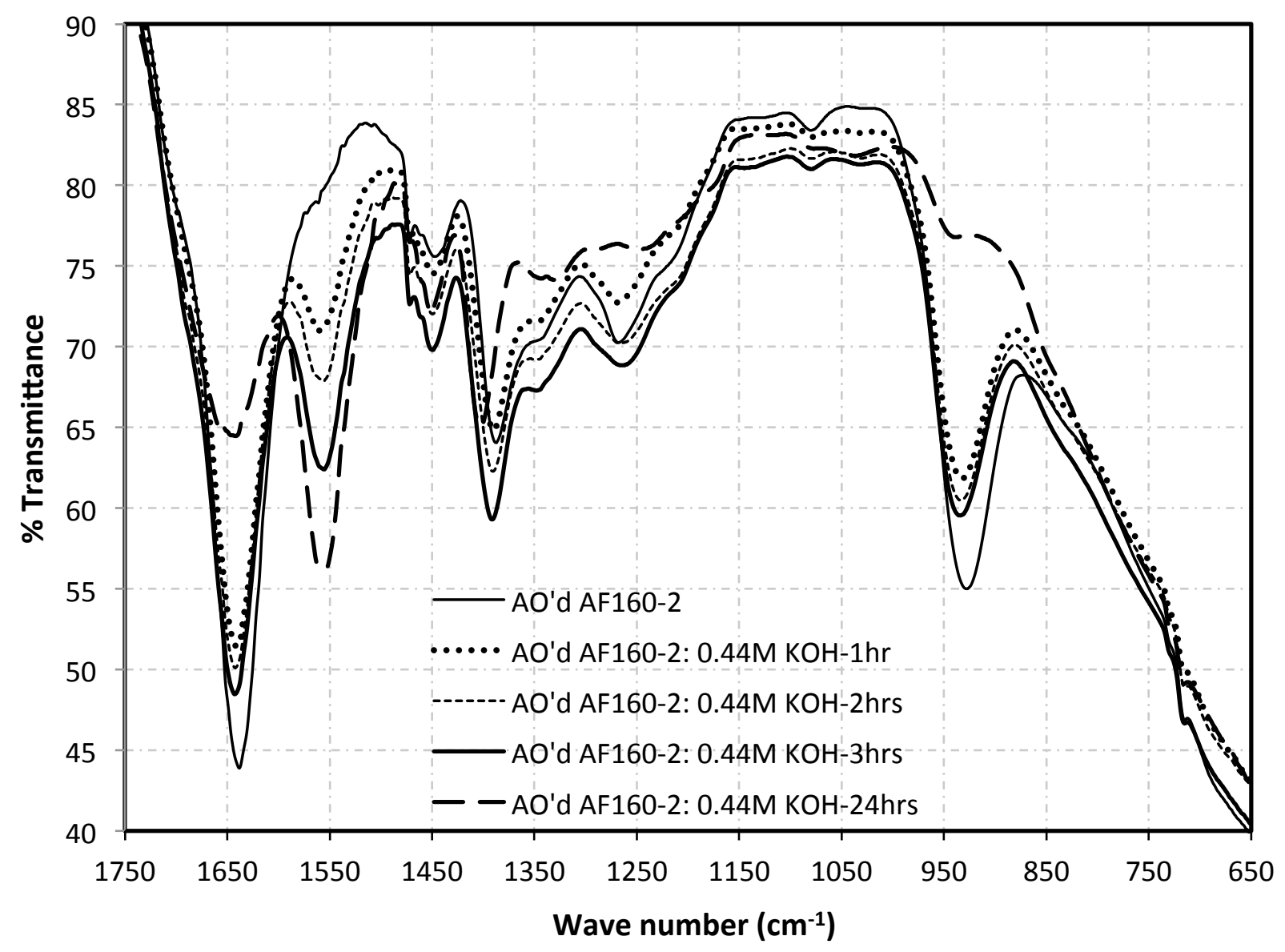

Figure 5. IR spectra of amidoximated AFI60-2 fiber after $0.44 \mathrm{M} \mathrm{KOH}$ conditioning for different time periods.

Table 3. $\%$ Transmittance $(\% \mathrm{~T})$ ratios among the different functional groups in AF160-2 adsorbent before and after $0.44 \mathrm{M} \mathrm{KOH}$ conditioning at $80{ }^{\circ} \mathrm{C}$ for different time periods shown in Figure 5.

\begin{tabular}{|c|c|c|c|}
\hline \multirow[b]{2}{*}{$\begin{array}{c}\text { Conditioning time of } \\
\text { amidoximated AF160-2 }\end{array}$} & \multicolumn{3}{|c|}{$\%$ T Ratio } \\
\hline & $\begin{array}{l}\mathrm{COO}^{-}\left(1565 \mathrm{~cm}^{-1}\right) \\
/ \mathrm{C}=\mathrm{N}\left(1644 \mathrm{~cm}^{-1}\right)\end{array}$ & $\begin{array}{l}\mathrm{N}-\mathrm{O}\left(935 \mathrm{~cm}^{-1}\right) / \\
\mathrm{C}=\mathrm{N}\left(1644 \mathrm{~cm}^{-1}\right)\end{array}$ & $\begin{array}{l}\mathrm{C}-\mathrm{N}\left(1277 \mathrm{~cm}^{-1}\right) / \\
\mathrm{C}=\mathrm{N}\left(1644 \mathrm{~cm}^{-1}\right)\end{array}$ \\
\hline Without $\mathrm{KOH}$ & - & 1.253 & 1.601 \\
\hline $0.44 \mathrm{M} \mathrm{KOH} \mathrm{-} 1$ hour & 0.725 & 1.202 & 1.414 \\
\hline $0.44 \mathrm{M} \mathrm{KOH} \mathrm{-} 2$ hours & 0.738 & 1.207 & 1.401 \\
\hline $0.44 \mathrm{M} \mathrm{KOH}-3$ hours & 0.777 & 1.228 & 1.420 \\
\hline $0.44 \mathrm{M} \mathrm{KOH} \mathrm{-} 24$ hours & 1.146 & $\begin{array}{l}\mathrm{N}-\mathrm{O} \text { stretch shifted } \\
\text { to } 950 \mathrm{~cm}^{-1}\end{array}$ & $\begin{array}{c}\text { C-N stretch shifted } \\
\text { to } 1341 \mathrm{~cm}^{-1}\end{array}$ \\
\hline
\end{tabular}



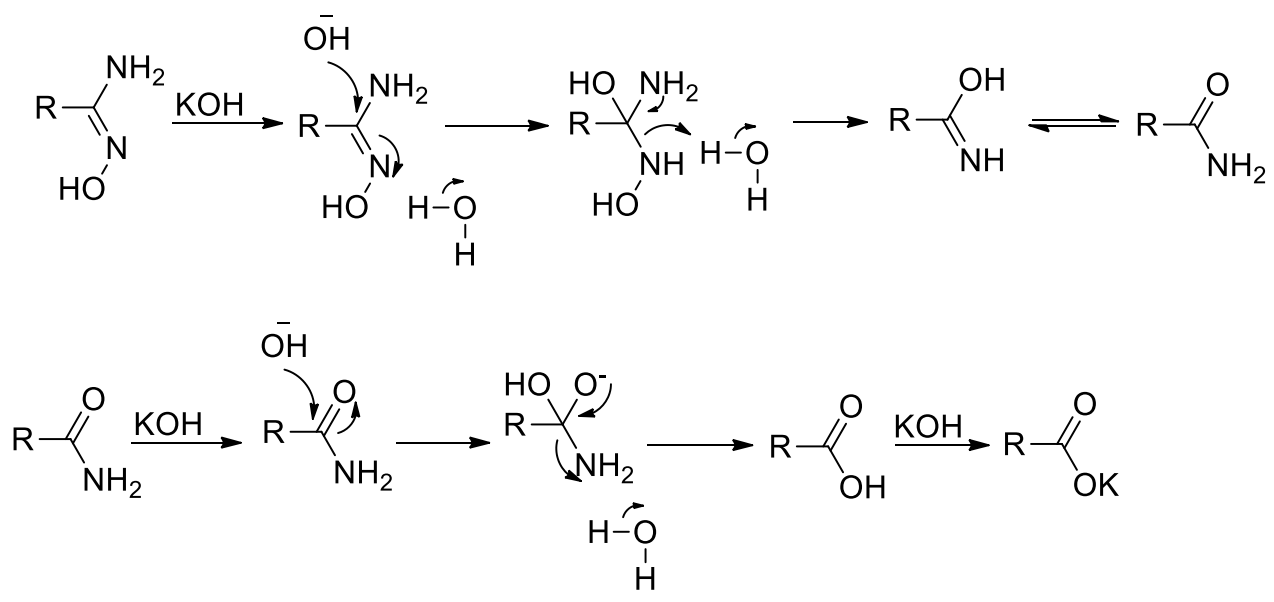

Figure 6. Proposed mechanism of formation of amide and/or carboxylate from amidoxime on reaction with $0.44 \mathrm{M} \mathrm{KOH}$ at $80^{\circ} \mathrm{C}$.

The reported $\mathrm{pk}_{\mathrm{a}}$ of amidoxime group is $10.7-10.8$ for succinediamidoxime. ${ }^{23}$ Therefore, the amidoxime groups present in the AF160-2 adsorbent are prone to be deprotonated in a strong base like $0.44 \mathrm{M} \mathrm{KOH}$ (the calculated $\mathrm{pH}$ is 13.6). Bromberg et al. illustrated that heating the amidoxime in the presence of water could convert it to hydroxamic acid, which further hydrolyses into acrylic acid. ${ }^{24}$ The degradation of amidoxime to carboxylate occurs during the $\mathrm{KOH}$ treatment (Figure 6). Carboxylate formation can be supported by the increase of the oxygen content of the fibers (Table 1), as well as the peak intensity increase at $1565 \mathrm{~cm}^{-1}$ vibrational stretching (Figure 5). The formation of carboxylate from amidoxime during $\mathrm{KOH}$ conditioning was previously demonstrated on small molecule model compounds. ${ }^{21}$ Similar conversion can also be observed using solid-state NMR after treatment of the AF160-2 fiber with $\mathrm{KOH}$ at $80^{\circ} \mathrm{C}$ for three hours (Figure 7). The increase in the peak at $180 \mathrm{ppm}$ is ascribed to the increased content of carboxylate, as shown in Figure 6. Moreover, the small peak at $157 \mathrm{ppm}$ represents a cyclic imidedioxime through cyclization of adjacent amidoximes (eq. 3). The cyclic imidedioxime is assumed to play an important role in the uptake of uranyl ions.

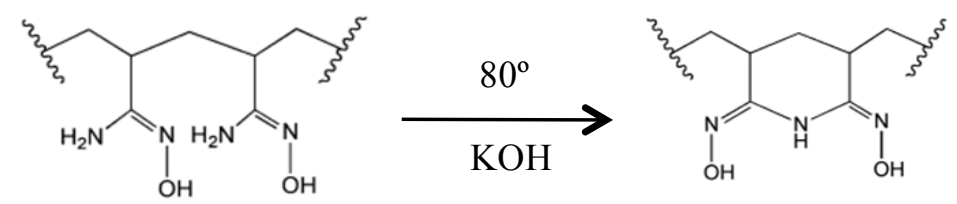




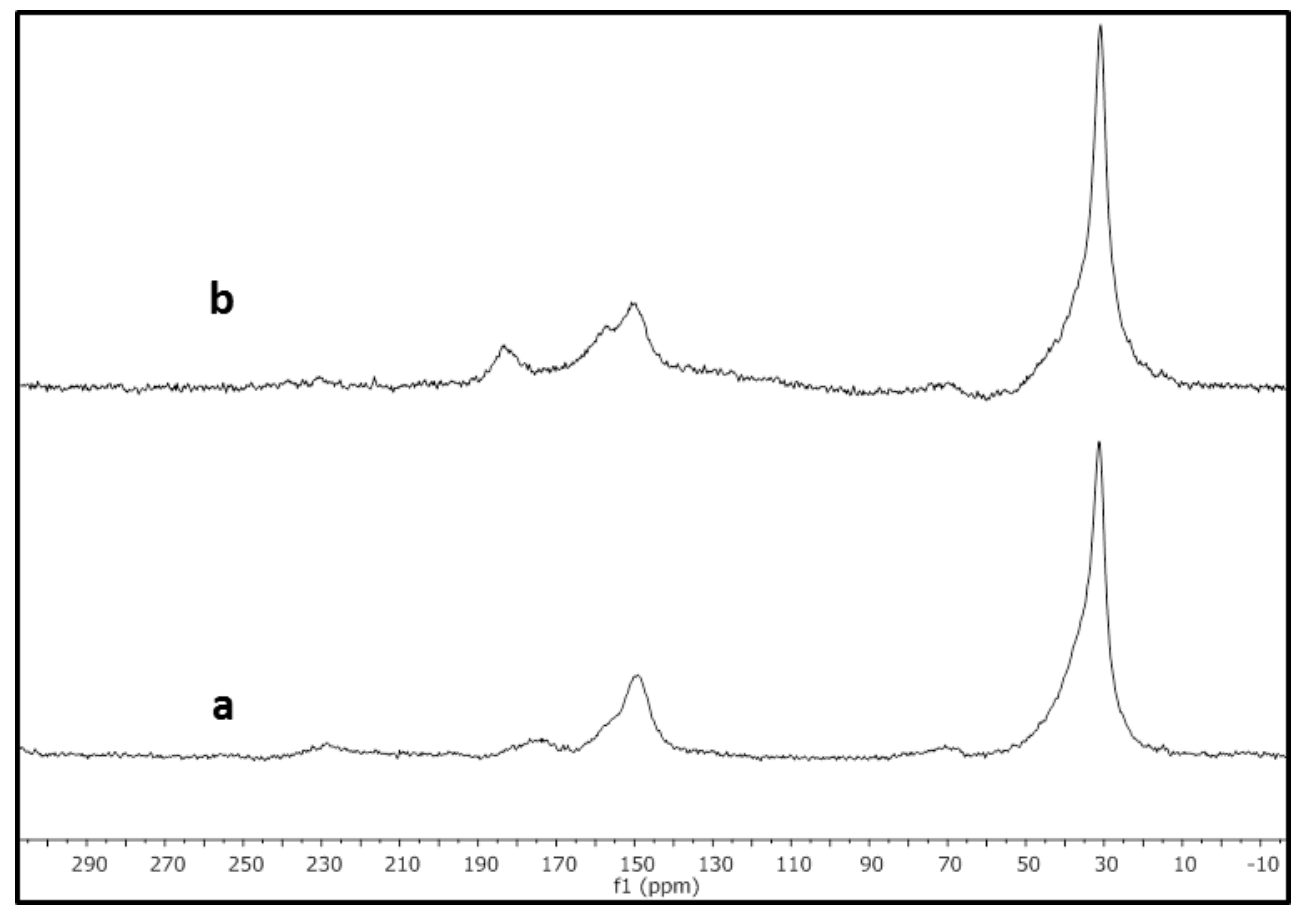

Figure 7. The solid state NMR of amidoximated fiber (a) and the fiber after $\mathrm{KOH}$ treatment for three hours at $80^{\circ} \mathrm{C}(\mathrm{b})$.

\section{Simulated seawater screening}

The uranium loading capacities of AF160-2 without $\mathrm{KOH}$ conditioning was found to be zero after 24 hours of contact with the 8-ppm $U$ simulated seawater screening solution. The uranium loading capacities of AF160-2 after conditioning with $0.2 \mathrm{M}, 0.44 \mathrm{M}$, and $0.6 \mathrm{M} \mathrm{KOH} \mathrm{(1} \mathrm{mg}$ adsorbent per $\mathrm{mL}$ base solution) at $60^{\circ} \mathrm{C}, 70^{\circ} \mathrm{C}$, and $80{ }^{\circ} \mathrm{C}$ for 1 hour, 2 hours, and 3 hours are shown in Figure 8. The adsorption capacity was higher with higher $\mathrm{KOH}$ concentration for any conditioning time period and temperature. Results shown in Figure 8, demonstrate a trend for the adsorbent performance in terms of uranium adsorption capacity with $\mathrm{KOH}$ concentration: $0.6 \mathrm{M}$ $>0.44 \mathrm{M}>0.2 \mathrm{M}$. Uranium adsorption gradually increases with conditioning time (i.e., $1 \mathrm{~h}$ through $3 \mathrm{~h}$ ) using $0.2 \mathrm{M}$ and $0.44 \mathrm{M} \mathrm{KOH}$. It is also notable that there is no further significant increment of uranium adsorption after $0.6 \mathrm{M} \mathrm{KOH}$ conditioning at $80^{\circ} \mathrm{C}$. 


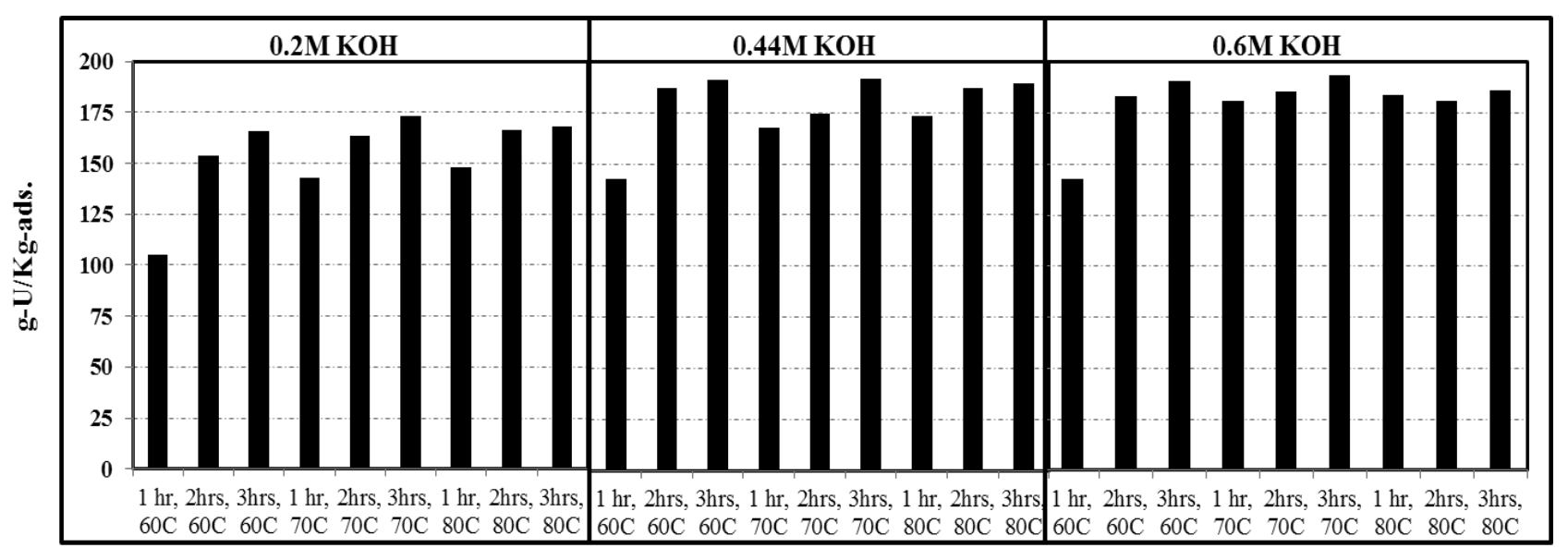

Time and Temperature

Figure 8. Uranium loading capacities of AF160-2 after $24 \mathrm{~h}$ in screening solution, spiked with uranyl ions at 7-8 ppm, after conditioning with $15 \mathrm{~mL}$ of $0.2 \mathrm{M}, 0.44 \mathrm{M}$, and $0.6 \mathrm{M}$ $\mathrm{KOH}$ at $60{ }^{\circ} \mathrm{C}, 70{ }^{\circ} \mathrm{C}$, and $80{ }^{\circ} \mathrm{C}$ for $1 \mathrm{~h}, 2 \mathrm{~h}$, and $3 \mathrm{~h}$ duration at each $\mathrm{KOH}$ concentration.

\section{Uranium uptake kinetics in batch reactors}

The results of uranium uptake kinetics in 1-L seawater spiked with 75-ppb uranyl nitrate are shown in Figure 9. The rate of uranium uptake increases as the $\mathrm{KOH}$ conditioning time increases from 45 minutes up to 120 minutes. But the uranium uptake rate slows down after 180 minutes $\mathrm{KOH}$ conditioning of the adsorbent. It is also notable that the total uranium uptake capacities after $\mathrm{KOH}$ conditioning for 75,120 , and 180 minutes are comparable, despite the fact that the rate of uptake decreases for $180 \mathrm{~min}(3 \mathrm{~h}) \mathrm{KOH}$ conditioning. These results indicate that $\mathrm{KOH}$ conditioning for a longer time-period may not be helpful for higher uranium uptake capacity from real seawater. 


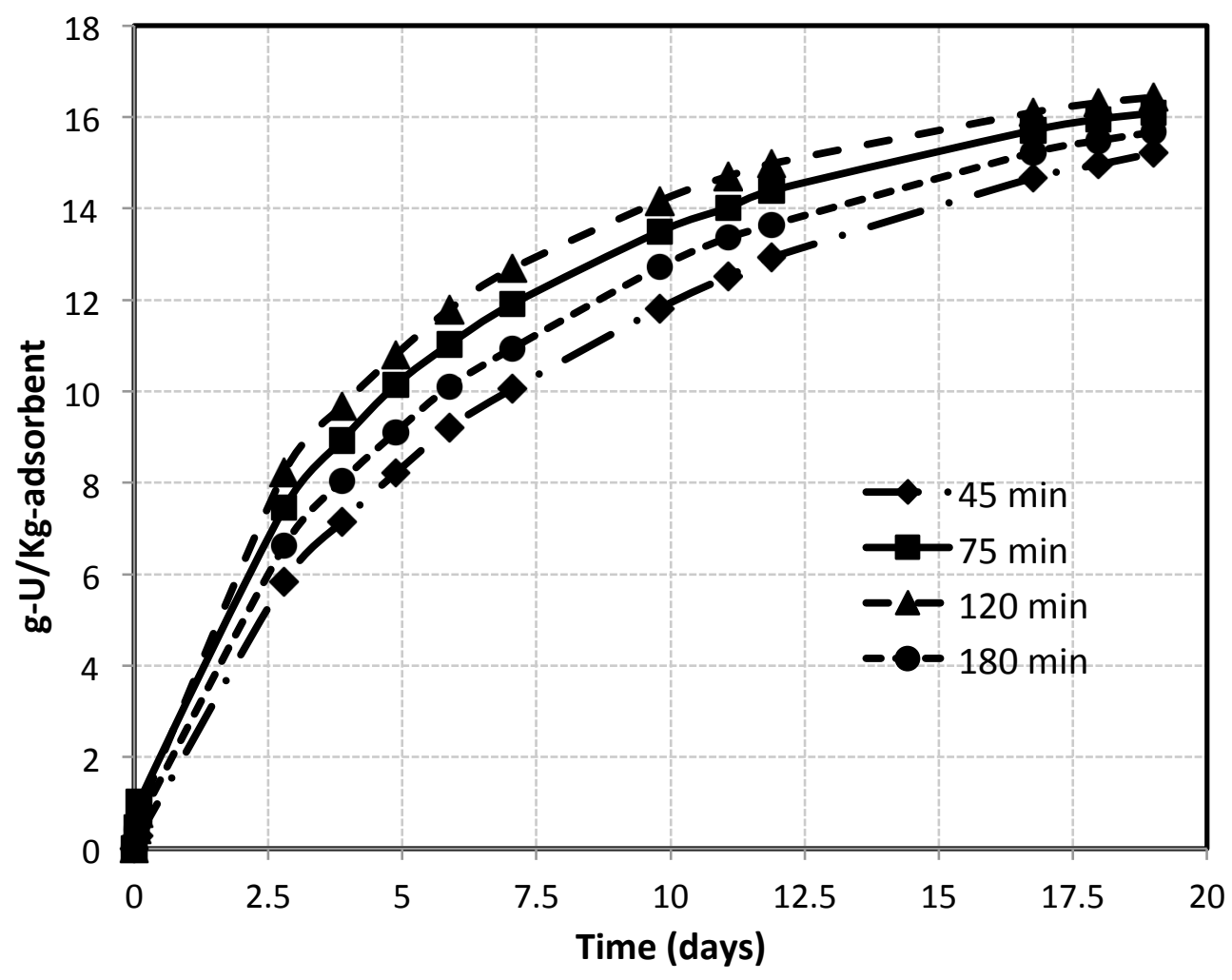

Figure 9. The rates of uranium uptake by AF160-2 adsorbent from 1-L seawater spiked with 75ppb uranyl nitrate. The adsorbent fibers were conditioned with $0.44 \mathrm{M} \mathrm{KOH}$ for 45, 75, 120 and $180 \mathrm{~min}$ at $80^{\circ} \mathrm{C}$, prior to addition in seawater.

\section{Field seawater testing}

The AF160-2 adsorbent performance with natural seawater, carried out at PNNL-MSL with filtered water from Sequim bay for 56 days in flow-through columns, is shown in Figure 10. The amidoximated AF160-2 adsorbent samples were treated with $0.44 \mathrm{M} \mathrm{KOH}$ at three different temperatures, i.e., $60{ }^{\circ} \mathrm{C}, 70^{\circ} \mathrm{C}$, and $80{ }^{\circ} \mathrm{C}$ for three different time periods, i.e., $1 \mathrm{~h}, 2 \mathrm{~h}$, and $3 \mathrm{~h}$ at each temperature. As can be seen in Figure 10, the uranium adsorption capacity after $\mathrm{KOH}$ conditioning at $70{ }^{\circ} \mathrm{C}$ is higher than that after $\mathrm{KOH}$ conditioning at $60{ }^{\circ} \mathrm{C}$. It is also notable that the uranium adsorption does not vary significantly with $\mathrm{KOH}$ conditioning time at $70{ }^{\circ} \mathrm{C}$. More interestingly, although AF160-2 has the highest uranium adsorption ( $\sim$ g-U/Kg-ads.) after $\mathrm{KOH}$ conditioning at $80^{\circ} \mathrm{C}$ for one hour, the capacity gradually decreases with increasing conditioning time from one hour to three hours. These results suggest that: 1) base-conditioning of the adsorbent is necessary in enhancing the uranium adsorption capacity and 2) longer alkaline 
contact at $80^{\circ} \mathrm{C}$ reduces the uranium adsorption capacity. Thus, conditioning of the AF160-2 adsorbent with $0.44 \mathrm{M} \mathrm{KOH}$ at $80^{\circ} \mathrm{C}$ for one hour can be considered optimal for highest uranium uptake capacity. Adsorption of other metal ions such as $\mathrm{V}, \mathrm{Fe}, \mathrm{Cu}$, and $\mathrm{Zn}$ from seawater is shown in Figure 11. It is notable that adsorption of vanadium was significantly higher, as compared to that of uranium. The iron uptake was comparable to uranium uptake. It is also interesting to see that uptake of vanadium and iron gradually decreases with increasing $\mathrm{KOH}$ conditioning time from one hour through three hours at $80^{\circ} \mathrm{C}$, while uptake of zinc slightly increases. It could, therefore, be briefed that the uptake of $\mathrm{V}, \mathrm{Fe}$, and $\mathrm{Cu}$ follows the same trend as that of uranium in both of the above conditioning parameters, while the uptake of $\mathrm{Zn}$ does not.

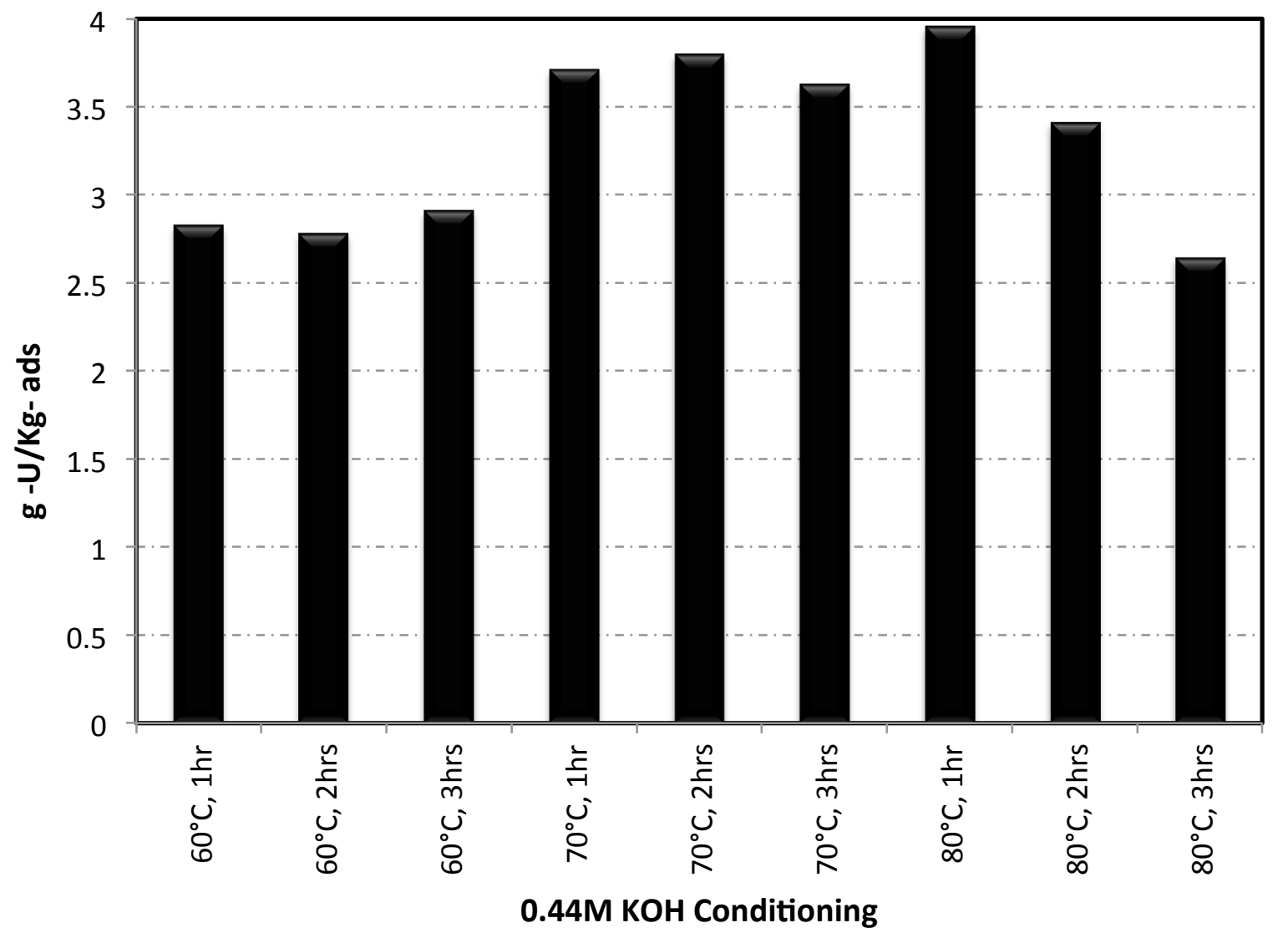

Figure 10. Uranium adsorption capacities of AF160-2 after 56 days contact with Sequim bay seawater in flow-through columns. The adsorbent samples were treated with $0.44 \mathrm{M}$ $\mathrm{KOH}$ at $60{ }^{\circ} \mathrm{C}, 70{ }^{\circ} \mathrm{C}$, and $80^{\circ} \mathrm{C}$ for three time periods i.e., $1 \mathrm{~h}, 2 \mathrm{~h}$, and $3 \mathrm{~h}$ at each temperature. 


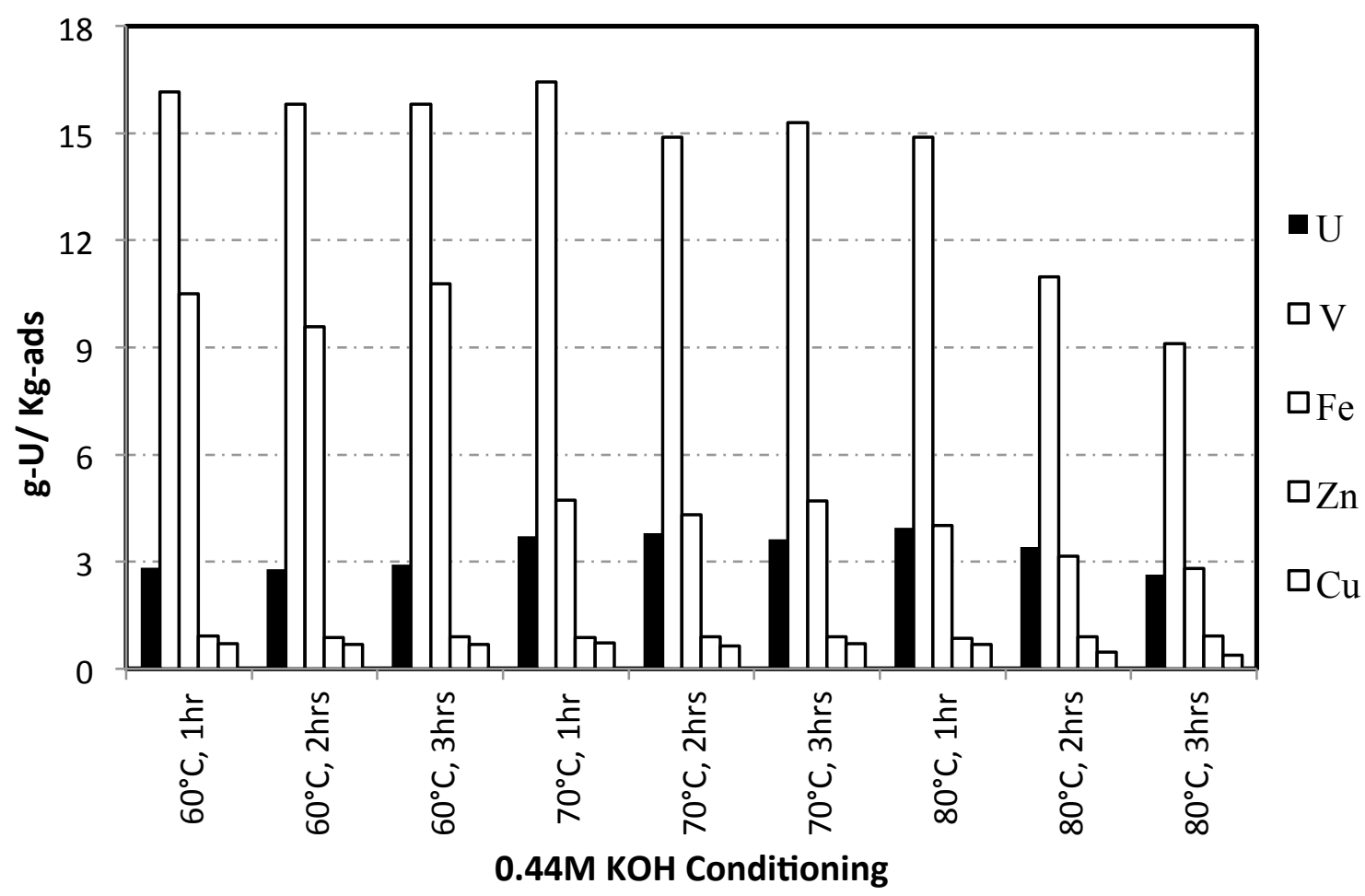

Figure 11. Loading of $\mathrm{U}, \mathrm{V}, \mathrm{Fe}, \mathrm{Zn}, \mathrm{Cu}, \mathrm{Ca}$ and $\mathrm{Mg}$ by AF160-2 after 56 days contact with seawater in flow-through columns. The adsorbent samples were treated with $0.44 \mathrm{M}$ $\mathrm{KOH}$ at $60{ }^{\circ} \mathrm{C}, 70{ }^{\circ} \mathrm{C}$, and $80{ }^{\circ} \mathrm{C}$ for three time periods i.e., $1 \mathrm{~h}, 2 \mathrm{~h}$, and $3 \mathrm{~h}$ at each temperature.

It was also observed that adsorption of $\mathrm{Ca}^{2+}$ and $\mathrm{Mg}^{2+}$ increases, as the $\mathrm{KOH}$ conditioning period increases, which is similar to the behavior of $\mathrm{Zn}^{2+}$. This phenomenon is probably due to the formation of more carboxylates with increasing $\mathrm{KOH}$ conditioning time, leading to more degradation of selective binding $\mathrm{AO}$ sites. This trend was not obvious in laboratory experiments because the equilibrating solution did not comprise $\mathrm{Ca}, \mathrm{Mg}, \mathrm{V}$, and other competing ions.

\section{Conclusions}

Simulated seawater screening tests with high uranyl concentration showed that the uranium adsorption capacity increased with an increase in the $\mathrm{KOH}$ concentration and conditioning time and temperature at each of the $\mathrm{KOH}$ concentrations. The FTIR and solid state NMR studies indicated that $\mathrm{KOH}$ conditioning converts the amidoxime functional groups into more 
hydrophilic carboxylate and cyclic imidedioxime. The longer the $\mathrm{KOH}$ conditioning time, up to three hours, the higher is the loading capacity from the simulated seawater screening solution, which is composed of only uranyl, sodium, chloride, and carbonate ions. Field testing with natural seawater showed that the uranium adsorption capacity of AF160-2 increased with $\mathrm{KOH}$ $(0.44 \mathrm{M})$ conditioning temperature, and gradually decreased with increasing $\mathrm{KOH}$ conditioning time from one hour to three hours at $80{ }^{\circ} \mathrm{C}$. This behavior is due to the conversion of amidoxime to carboxylate. The carboxylate groups are needed to increase the hydrophilicity of the adsorbent; however, conversion of a significant amount of amidoxime to carboxylate leads to loss in selectivity toward uranyl ions. Thus, considering single use of the adsorbent, there is an optimum $\mathrm{KOH}$ conditioning time for each base-conditioning temperature at which an optimum ratio between amidoxime and carboxylate is reached. For the case of base conditioning with $0.44 \mathrm{M} \mathrm{KOH}$ at $80{ }^{\circ} \mathrm{C}$ the optimal conditioning time is approximately 1 hour, with respect to the highest uranium loading capacity from real seawater. It should be noted, however, that for multiple uses of the adsorbent involving several adsorption/elution cycles, if base-conditioning has to be performed before each adsorption cycle, a less than the optimum time period should be used each time. This is because of the fact that the conversion of amidoxime to carboxylate is irreversible, which means that the density of carboxylate groups will keep increasing as the number of adsorption/elution cycles increases. Thus, in a real adsorbent deployment scenario, if base-conditioning has to be performed before adsorption, its duration should be determined based on the expected number of cycles. For example, if six is the most economical number of cycles, using amidoxime-based adsorbents, base conditioning before each adsorption step, with $0.44 \mathrm{M} \mathrm{KOH}$ at $80{ }^{\circ} \mathrm{C}$, should last for $15-20 \mathrm{~min}$.

Uptake of other metal ions such as $\mathrm{V}, \mathrm{Fe}$, and $\mathrm{Cu}$ follows the same trend as that of uranium. Also, the uptake of $\mathrm{Ca}, \mathrm{Mg}$, and $\mathrm{Zn}$ ions increased with increasing $\mathrm{KOH}$ conditioning time, probably due to formation of more carboxylates, which leads to conversion of uraniumselective binding sites to less selective sites.

The results of this study are useful in the selection of optimal values of the parameters involved in preparing amidoxime-based adsorbent for uranium uptake from seawater. Additional work is still needed to provide a complete understanding of the chemistry of base conditioning and its role on the functioning of the adsorbent. 


\section{References}

1. Scanlan, J. P. Equilibriums in uranyl carbonate systems. II. The overall stability constant of $\mathrm{UO}_{2}\left(\mathrm{CO}_{3}\right)_{2}{ }^{2-}$ and the third formation constant of $\mathrm{UO}_{2}\left(\mathrm{CO}_{3}\right)_{3}{ }^{4-}$. J. Inorg. Nucl. Chem. 1977, 39, 635 .

2. Hirotsu, T.; Katoh, S.; Sugasaka, K.; Seno, M.; Itagaki, T. Adsorption Equilibrium of Uranium from Aqueous [UO2(CO3)3]4-. Solutions on a Polymer Bearing Amidoxime Groups. J. Chem. Soc., Dalton Trans. 1986, 1983.

3. Kwon, W. J.; Yoo, C. E.; Chang, W.; Noh, Y.-S.; Suh, J. Metal sequestering by a poly(ethylenimine)-sephadex G-25 conjugate containing 2,2'-dihydroxyazobenzene. Bull. Korean Chem. Soc. 2000, 21, 393.

4. Kim, J.; Tsouris, C.; Mayes, R. T.; Oyola, Y.; Saito, T.; Janke, C. J.; Dai S.; Schneider, E.; Sachde, D. Recovery of Uranium from Seawater: A Review of Current Status and Future Research Needs. Sep. Sci. Technol. 2013, 48, 367.

5. Omichi, H; Katakai, A; Sugo, T.; Okamoto, A. A new type of amidoxime-groupcontaining adsorbent for recovery of uranium from seawater. III. Recycle use of adsorbent. Sep., Sci. Technol. 1986, 21, 536.

6. Egawa, H.; Kabay, N.; Shuto, T.; Jyo, A. Recovery of Uranium from Seawater. XII. Preparation and Characterization of Lightly Crosslinked Highly Porous Chelating Resins Containing Amidoxime Groups. J. Appl. Polym. Sci. 1992, 46, 129.

7. Egawa, H.; Nakayama, M.; Nonaka, T.; Sugihara, E. Recovery of Uranium from Sea Water. IV. Influence of Crosslinking Reagent on the Uranium Adsorption of Macroreticular Chelating Resin Containing Amidoxime Groups. J. Appl. Polym. Sci. 1987, 33, 1993.

8. Kabay, N.; Egawa, H. Chelating Polymers for Recovery of Uranium from Seawater, Sep., Sci. Technol. 1994, 29, 135.

9. Kabay, N. Preparation of Amidoxime-Fiber Adsorbents Based on Poly(Methacrylonitrile) for Recovery of Uranium from Seawater. Sep., Sci. Technol. 1994, 29, 375.

10. Kago, T.; Akira, G.; Kusakabe, K.; Morooka, S. Preparation and Performance of Amidoxime Fiber Adsorbents for Recovery of Uranium from Seawater. Ind. Eng. Chem. Res. 1992, 31, 204. 
11. Zhang, A.; Asakura, T.; Uchiyama, G. The adsorption mechanism of uranium(VI) from seawater on a macroporous fibrous polymeric adsorbent containing amidoxime chelating functional group. React. Funct. Polym. 2003, 57, 67.

12. Katragadda, S.; Gesser, H. D.; Chow, A. The extraction of uranium by amidoximated orlon. Talanta 1997, 45, 257.

13. Zhang, A.; Uchiyama, G.; Asakura, T. pH Effect on the uranium adsorption from seawater by a macroporous fibrous polymeric material containing amidoxime chelating functional group. React. Funct. Polym. 2005, 63, 143.

14. Das, S.; Pandey, A. K.; Athawale, A. A.; Manchanda, V. K. Exchanges of uranium (VI) species in amidoxime-functionalized sorbents. J. Phys. Chem. B. 2009, 113, 6328.

15. Das, S.; Pandey, A. K.; Athawale, A.; Kumar, V.; Bhardwaj, Y. K.; Sabharwal, S.; Manchanda, V. K. Chemical aspects of uranium recovery from seawater by amidoximated electron-beam-grafted polypropylene membranes. Desalination 2008, 232, 243.

16. Zhang, A.; Uchiyama, G.; Asakura, T. The adsorption properties and kinetics of uranium(VI) with a novel fibrous and polymeric adsorbent containing amidoxime chelating functional group from seawater. Sep. Sci. Technol. 2003, 38, 1829.

17. Zhang, A.; Uchiyama, G.; Asakura, T. Dynamic-state adsorption an elution behaviour of uranium(VI) ions from seawater by a fibrous and porous adsorbent containing amidoxime chelating functional groups. Adsorpt. Sci. Technol. 2003, 21, 761.

18. Seko, N.; Katakai, A.; Tamada, M.; Sugo, T.; Yoshii, F. Fine fibrous amidoxime adsorbent synthesized by grafting and uranium adsorption-elution cyclic test with seawater. Sep. Sci. Technol. 2005, 39, 3753.

19. Kobuke, Y.; Tanaka, H.; Ogoshi, H. Imidedioxime as a significant component in socalled amidoxime resin for uranyl adsorption from seawater. Polym. J. 1990, 22, 179.

20. Astheimer, L.; Schenk, H. J.; Witte, E. G.; Schwochau, K. Development of sorbers for the recovery of uranium from seawater. Part 2. The accumulation of uranium from seawater by resins containing amidoxime and imidoxime functional groups. Sep. Sci. Technol. 1983, 18, 307.

21. Kang, S. O.; Vukovic, S.; Custelcean, R.; Hay B. P. Cyclic Imide Dioximes: Formation and Hydrolytic Stability. Ind. Eng. Chem. Res. 2012, 51, 6619. 
22. Bernal, J. L.; del Nozal, M. J.; Deba'n, L.; del Valle, J. L.; Cerda', V.; Estela, J. M. Analytical properties of the amidoxime group. XII. Potentiometric and thermometric behavior of succinediamidoxime. J. Therm. Anal. 1986, 31, 931.

23. Broberg, L.; Schreuder-Gibson, H; Creasy, W.R.; McGarvey, D.J.; Fry, R.A.; Hatton, T.A. Degradation of Chemical Warfare Agents by Reactive Polymers, Ind. Eng. Chem. Res. 2009, 48, 1650. 